\title{
Desain Rancang Bangun Dapur Umum Por- table Dalam Penanggulangan Bencana Alam
}

\author{
Andi Farid Hidayanto ${ }^{1}$, Anna Rulia ${ }^{2}$ \\ ${ }^{1}$ Program Studi Desain Produk, Jurusan Desain, Politeknik Negeri Samarinda \\ Jl. Ciptomangunkusumo, Samarinda, 75131 Telp. 0541260588
}

\begin{abstract}
Indonesia is a disaster-prone areas. To meet the logistical needs of the victim and the officer needed a common kitchen. Common kitchen that is generally in the form of tents, buildings used as shelters, or modified car. Common kitchen there is an emergency nature, improvise, and how far from the disaster site. These problems need to design a common kitchen for natural disaster management, which can meet the needs, the officer and the victim. In designing methods Pahl and Beitz with steps Planning and explanation of the task, design concept, design forms, and design details. Collecting data using methods Individual Questionnaire and Focus Group Discussion the results obtained attributes required in the design. Results of the research is a common kitchen design for a natural disaster are portable, easily assembled and disassembled, can be set up in various locations condition, easy to operate, able to accommodate facilities and needs. Common kitchen design produced in the form of large-scale three-dimensional model, a blueprint for the technical specifications, and the protoype.
\end{abstract}

Keywords: natural disasters; design; soup kitchen; portable.

\begin{abstract}
ABSTRAK
Indonesia merupakan daerah rawan bencana. Untuk memenuhi kebutuhan logistik korban dan petugas diperlukan dapur umum. Dapur umum yang ada umumnya berupa tenda peleton, bangunan yang dijadikan posko, atau mobil yang dimodifikasi. Dapur umum yang ada sifatnya darurat, seadanya dan lokasinya jauh darilokasi bencana. Dari masalah tersebut perlu desain dapur umum untuk penanggulangan bencana alam, yang bisa memenuhi kebutuhan, petugas maupun korban. Dalam mendesain menggunakan metode Pahl dan Beitz dengan langkah-langkah Perencanaan dan penjelasan tugas, Perancangan konsep, Perancangan bentuk, dan Perancangan detail. Pengumpulan data menggunakan metode Individual Questionnaire dan Focus Group Discussion yang hasilnya didapatkan atribut yang diperlukan dalam desain. Hasil dari penelitian berupa desain dapur umum untuk penanggulangan bencana alam yang portable, mudah dirakit dan dibongkar, bisa didirikan di lokasi yang beraneka kondisi, mudah dioperasikan, mampu menampung fasilitas dan kebutuhan. Desain dapur umum yang dihasilkan dalam bentuk model tiga dimensi berskala, blue print spesifikasi teknis, dan protoype.
\end{abstract}

Kata kunci: bencana alam; desain; dapur umum; portable 


\section{PENDAHULUAN}

Indonesia merupakan daerah rawan bencana. Akhir-akhir ini sering terdengar berita bencana yang melanda di wilayah Indonesia. Antara lain banjir, kebakaran, gempa, gunung meletus, longsor, kecelakaan di sungai, daerah terisolir, kerusakan alam akibat tambang. Dalam menangani penanggulangan bencana, seperti dalam pemenuhan kebutuhan logistik, utamanya makan untuk para korban dan petugas, diperlukan dapur umum.

Dapur umum untuk penanggulangan bencana alam yang ada saat ini biasanya dari tenda peleton, rumah/posko yang dijadikan dapur atau mobil lapangan. Pendirian dapur umum saat ini masih dianggap seadanya, seperti tenda yang diikat ke pohon, rumah penduduk yang dijadikan posko, atau mobil terbuka. Dapur umum yang ada juga belum bisa menampung fasilitas pendukung, misalnya ruang istirahat, peralatan, tempat logistik, dan ruang beraktifitas. Dimensi dan ruang dapur umum juga terbatas sehingga gerak aktiftas tidak leluasa (Arie Sulistyanto, 2009).

Lantai dapur umum yang ada umumnya kontak langsung dengan tanah dan tidak terlindungi dari efek hujan, becek, tanah gembur dan tanah tidak rata. Akibatnya lantai mudah kotor dan tidak higienis. Posisi petugas beraktifitas di dalamnya tidak ergonomis, sehingga jika dilakukan dalam jangka waktu lama tidak nyaman dan menimbulkan kelelahan (Terbit Setya). Karena bersifat darurat, pendirian dapur umum mengutamakan kecepatan yang sering tanpa diimbangi persiapan matang. Tidak jarang fasilitas yang ada tidak memadai dan ribet dalam penataan peralatan (Dyat Agung). Pendirian dapur umum juga jauh dari lokasi bencana, karena tidak bisa dirakit di tempat kejadian bencana.

Dari kondisi tersebut diperlukan dapur umum untuk bencana, dimana dapur umum tersebut bersifat kompak, mudah dalam pengoperasian, dapat dipindahpindah, mampu menampung peralatan yang diperlukan, dan fasilitas yang dibutuhkan petugas. Dapur umum bisa dikomposisikan dengan tenda-tenda lainnya, secara modular. Dapur umum hasil desain bisa diaplikasikan untuk beberapa pengguna, antara lain pemerintah daerah, PMI, Dinas Sosial, dan lembaga yang berkepentingan dengan dapur umum. Dapur umum yang didesain bersifat portable, sehingga bisa dikirim ke tempat yang memerlukan. Proses pembuatannya bisa di industri manufaktur sederhana, sehingga bisa diproduksi massal untuk menekan biaya produksi.

\section{METODE}

Perancangan merupakan kegiatan awal dari usaha merealisasikan suatu produk yang kebutuhannya sangat dibutuhkan oleh masyarakat. Setelah perancangan selesai maka kegiatan yang menyusul adalah pembuatan produk. Kedua kegiatan tersebut dilakukan beberapa orang atau kelompok dengan keahlian masing-masing, yaitu perancangan dilakukan oleh tim perancang dan pembuatan produk oleh tim kelompok pembuat produk. Dalam mendesain produk ini penulis menggunakan metode dan langkah-langkah desain dari Pahl dan Beitz.

Pahldan Beitz mengusulkan cara merancang produk sebagaimana yang dijelaskan dalam bukunya; Engineering Design: A Systematic Approach. Cara merancang Pahl dan Beitz tersebut terdiri dari 4 kegiatan atau fase, yang masingmasing terdiri dari beberapa langkah. Keempat fase tersebut adalah: 
1. Perencanaan dan penjelasan tugas

2. Perancangan konsep produk

3. Perancangan bentuk produk (embodiment design)

4. Perancangan detail

Setiap fase proses perancangan berakhir pada hasil fase. Hasil setiap fase tersebut kemudian menjadi masukan untuk fase berikutnya dan menjadi umpan balik untuk fase yang mendahului. Hasil tiap fase dapat berubah oleh umpan balik yang diterima dari hasil fase-fase berikutnya. Fase-fase ini menyusun spesifikasi produk yang mempunyai fungsi khusus dan karakteristik tertentu yang memenuhi kebutuhan masyarakat. Produk hasil desain ini dengan fungsi dan karakteristik yang dihasilkan tersebut merupakan olahan hasil survei bagian pemasaran atau atas permintaan segmen masyarakat. Dalam tiap fase dikumpulkan informasi tentang persyaratan (requirement) yang harus dipenuhi oleh produk dan kendala-kendala yang merupakan batas-batas untuk produk. Hasil tiap fase adalah spesifikasi produk yang dimuat dalam suatu daftar persyartan teknis.

\section{HASIL DAN PEMBAHASAN}

Dalam mendesain tenda dapur umum ini ditentukan dulu kriteria-kriteria desainnya. Hal ini digunakan sebagai acuan desain yang akan dihasilkan. Adapun kriteria tersebut yaitu:

1. Material. Dapur menggunakan metarial yang aman. Tidak mudah terbakar, mudah dibentuk, tidak mudah sobek danmudah didapatkan di pasaran.

2. Ruang. Dapur memiliki dimensi cukup memenuhi untuk beraktifitas petugas di dalamnya. Mampu menampung logistik dan peralatan memasak. Tersedia ruang terbuka dan ruang tertutup untuk halhal yang tidak diakses oleh umum.
3. Proses produksi. Dapur bisa diproduksi di industri manufaktur sederhana.

4. Alur sirkulasi. Dapur memper-timbangan faktor ergonomi dan anthropometri untuk kenyamanan dan keamanan, ruang sirkulasi,alur keluar masuk, serta alur beraktifitas di dalamnya. Memiliki area pandang yang bebas. Tertata sirkulasi udara, supaya suhu di dalamnya nyaman untuk aktifitas.

5. Tanda/sign. Dapur memiliki tandatanda yang menunjukkan identitas, seperti tanda dapur, identitas area, corporate identity.

6. Pemasangan. Tenda didesain mudah untuk dibongkar/pasang. Tenda terdiri dari beberapa komponen yang mudah diurai atau disusun, meliputi alas, kerangka, badan tenda. Tenda bisa dirangkai dengan tenda sejenis, bila di lokasi memerlukan komposisi dari beberapa tenda. Dapur bersifat mobile dan portable, agar bisa dikirim ke lokasi dengan medan berbagai kondisi.

7. Desain. Dapur umum memiliki unsur estetika (desain) yang indah sesuai kaidah desain yang baku, sebagai state of the art maupun point of view suatu produk.

Dalam desain dapur umum didata aktiftas yang terjadi di dalamnya. Dari aktifitas-aktifitas tersebut akan diperoleh kebutuhan yang diperlukan. Beberapa aktifitas tersebut antara lain:

Dari aktifitas tersebut akan didapat data kebutuhan dalam dapur yang memerlukan fasilitas. Kebutuhan tersebut bisa merupakan bagian dari desain dapur, namun bisa juga bukan dari desain dapur. Tentunya dengan menempatkan fasilitas dalam dapur, dan fasilitas tersebut diperoleh dari luar. Sehingga fasilitas tersebut bukan merupakan bagian dari desain dapur 
Tabel 1. Aktiftas di dapur

\begin{tabular}{lll}
\hline No. & \multicolumn{1}{c}{ Aktifitas } & \multicolumn{1}{c}{ Kebutuhan } \\
\hline 1. & Keluar/masuk tenda & Pintu \\
2. & Jalan, jongkok & Area sirkulasi \\
3. & Duduk, berdiri & Kursi, area sirkulasi \\
4. & Mengambil, menaruh barang & Lemari, rak, meja \\
5. & Mengambil membuang sampah & Tempat sampah \\
6. & Melihat tanda & Tanda petunjuk \\
7. & Proteksi dari tanah & Alas, lantai \\
8. & Memasak & Perkakas dapur \\
9. & meracik & Perkakas dapur \\
10. & Mendirikan, membongkar dapur & System \\
11. & Menyimpan dapur & System \\
\hline
\end{tabular}

umum. Fasilitas tersebut antara lain: meja, kursi, tempat sampah, perkakas memasak, pengatur udara.

Dalam mendesain produk, pertama yang ditetapkan adalah penentuan konsepnya. Karena dari konsep ini, semua unsur desain akan mengancu pada konsep tersebut. Konsep dari produk ini adalah modern minimalis. Desain produk

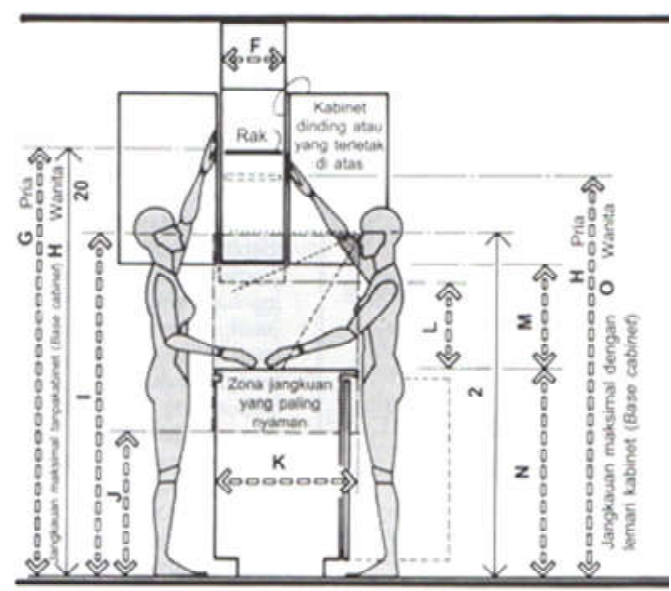

Gambar 1: mengacu pada konsep tersebut, meliputi desain, perakitan, material, warna, asesoris, detail. Desain berkesan modern, namun simpel, sederhana, fungsional. Selanjutnya dilakukan desain awal, yang terdiri dari beberapa alternatif desain. Dari beberapa alternatif desain, dipilih satu desain terpilih. Selanjutnya desain terpilih tersebut dikembangkan sehingga menjadi desain fi-

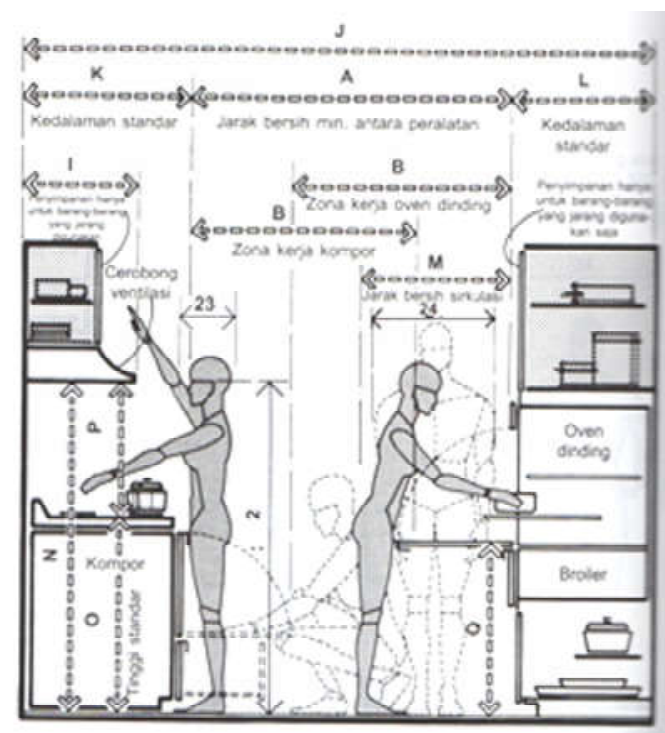

Gambar 2

Gambar 1-2. Acuan dimensi ruang Sumber: Julius Panero (1979) 
Tabel 2. Acuan Dimensi

\begin{tabular}{ccll}
\hline No. & Kode & \multicolumn{1}{c}{ Keterangan } & \multicolumn{1}{c}{ Dimensi (cm) } \\
\hline 1. & A & Jarak antar peralatan & 121,9 min \\
2. & G & Jangkauan tangan & 200 \\
3. & K & Lebar meja kerja/jarak perkakas ke dinding & $61-66$ \\
4. & M & Jarak Sirkulasi & 76,2 \\
5. & N & Tinggi meja kerja & $88,9-91,4$ \\
\hline
\end{tabular}

nal. Desain final tersebut dilengkapi spesifikasi teknis baku agar bisa diproduksi. Dari beberapa alternatif desain, terpilih desain final seperti gambar 3 di bawah ini.

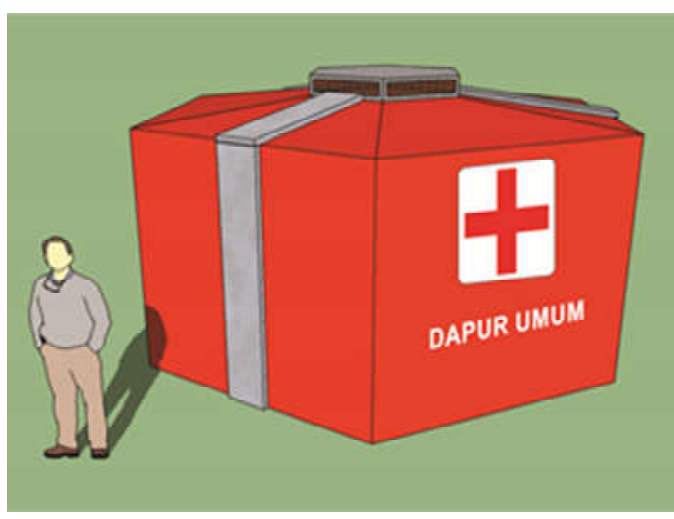

Gambar 3:

Isometri produk

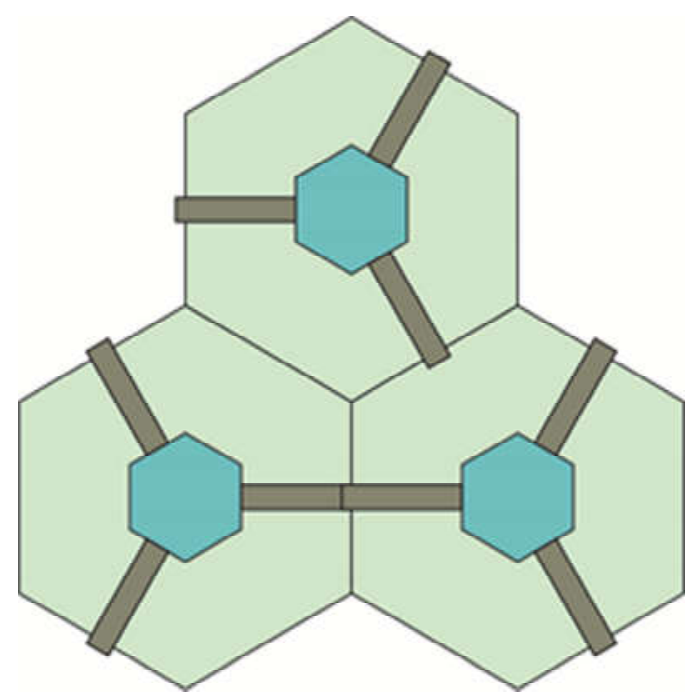

Gambar 4:
Dari desain terpilih, disusun beberapa alternatif konfigurasi ruang dalam dapur umum (lay-out) atau blocking area yang menunjukkan penempatan/akomodasi aktifitas dan fasilitas di dalamnya. Blocking area ini diperlukan untuk mengakomodasi aktifitas yang terjadi. Sehingga bisa tersusun penempatan perangkat, fasilitas, serta alur sirklulasi aktifitas di dalamnya. Konfigurasi ruang dalam dapur umum mengacu pada data anthropometri supaya didapatkan data dimensi sesuai kenyamanan petugasnya. Data anthropometri tersebut seperti ditunjukkan gambar di bawah ini. Alokasi blocking area mengacu pada data ergonomi untuk menentukan dimensi-dimensinya.

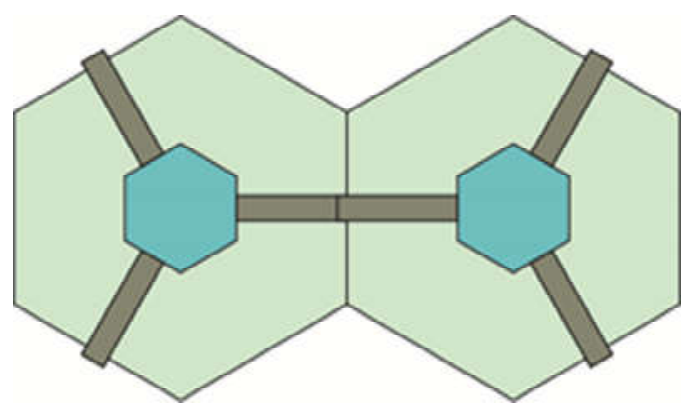

Gambar 5:

Gambar 4 - 5. Kombinasi Desain (Sumber: Penulis, 2015) 
Konfigurasi ruang tersebut seperti ditunjukkan dalam gambar 6 - 7 di bawah ini:

Dari blocking area, dikembangkan area sirkulasi aktifitas di dalamnya. Sehingga didapatkan data alur aktifitas dan kebutuhan dimensi ruang, untuk penempatan peralatan dan aktifitas petugas di dalamnya. Penentuan dimensi hasil blocking areabaku sesuai acuan data anthropometri serta toleransinya. Maka akan didapatkan ukuran teknis produk hasil desain. Hasil desain produk tersebut bisa dilihat pada gambar 9 di bawah ini:

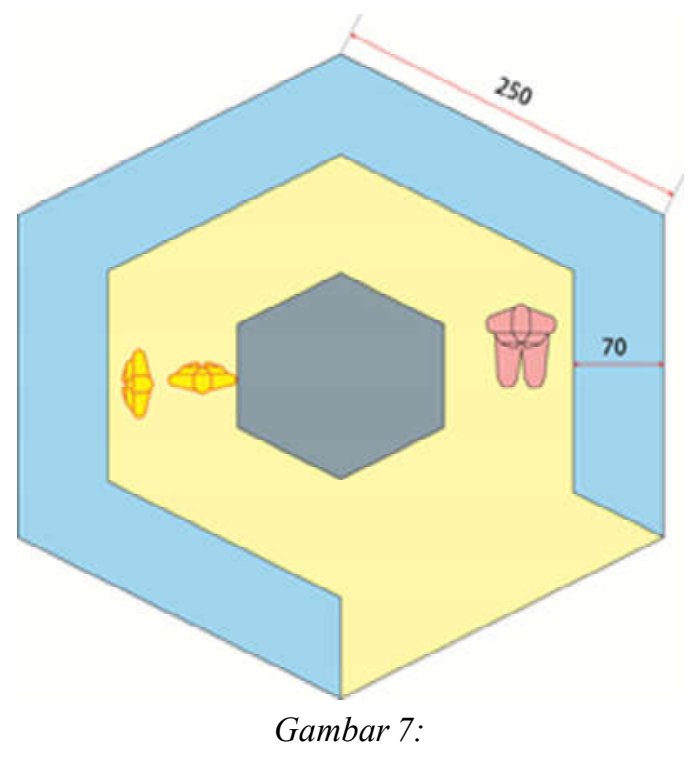

Pemberian warna pada produk merupakan hal penting sebagai bagian dari desain. Dengan penggunaan warna maka produk akan mudah dikenali oleh konsumen, memberi kesan menarik, dan mendukung konsep. Pemberian warna meliputi warna produk, asesoris (grafis), tanda-tanda (sign) petunjuk, keterangan, label.

Pemberian warna pada dapur umum tersebut yaitu:

1. Bodi. Menggunakan warna yang cerah, mudah dilihat dari jauh. Bodi meliputi dinding, atap. Warna yang cerah antara lain putih, oranye, hijau toska. Dalam hal ini digunakan warna oranye, sebagai pertimbangan warna ini lazim dipakai oleh badan penangggulangan bencana. Warna oranye mudah dilihat, tidak menyilaukan mata, bersifat hangat, memancarkan cahaya, sehingga cepat menarik perhatian.

2. Kerangka menggunakan warna dari material sendiri yang diekspos, yaitu warna galvanis. Untuk kerangka sisi penguat dinding menggunakan juga warna alami kerangka.

3. Ilustrasi dan tanda. Dalam tenda diberi ilustrasi dan tanda-tanda sebagai

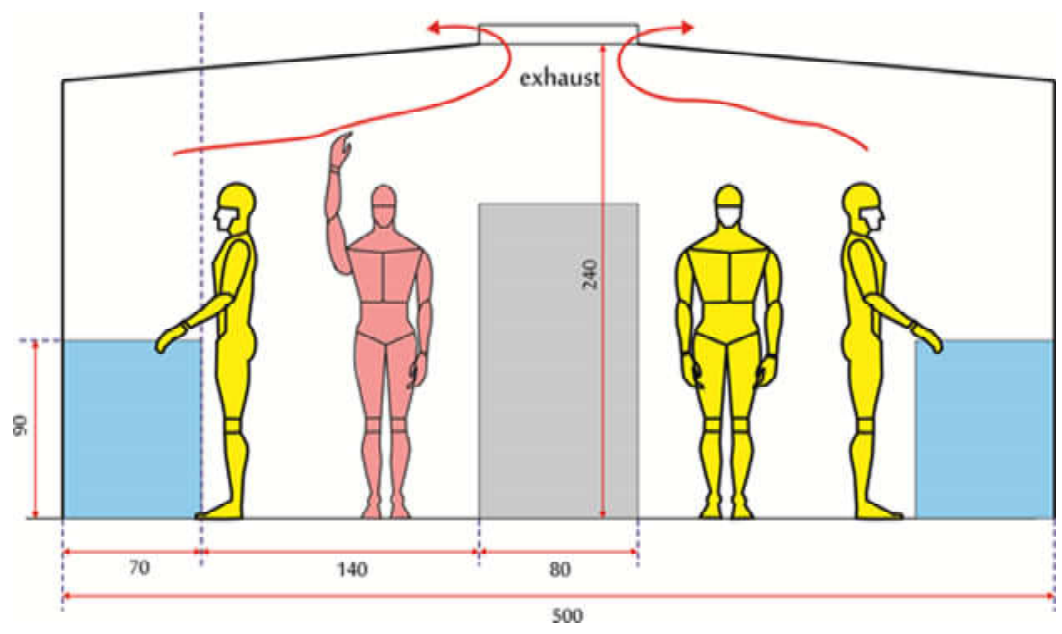

Gambar 6:

Gambar 6 - 7. Lay-out ruang

(Sumber: Penulis, 2015) 


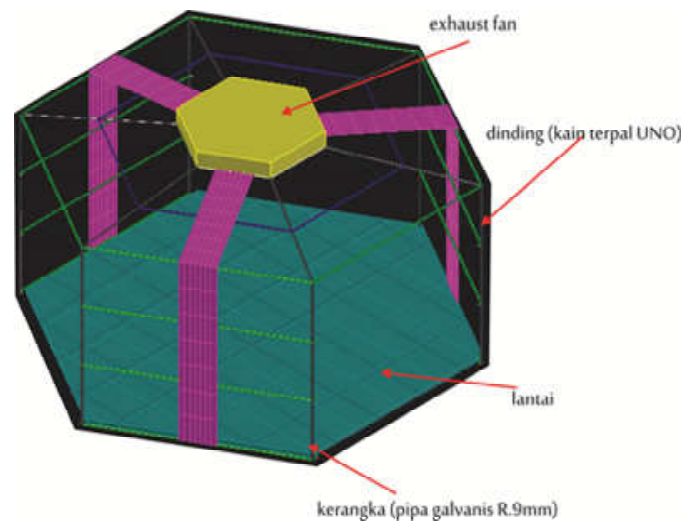

Gambar 8:

Konstruksi Produk

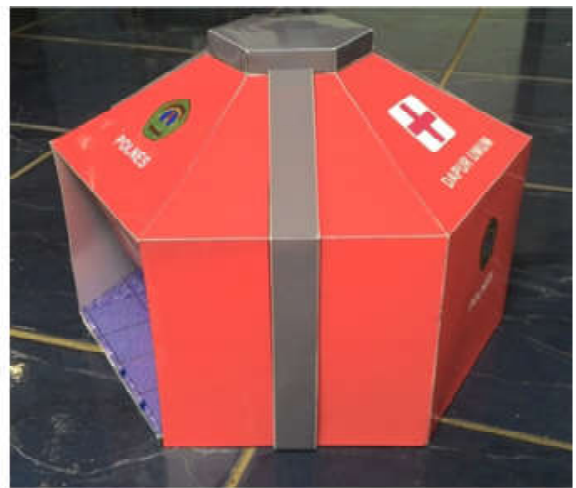

Gambar 9:

Model Skala

(Sumber: Penulis, 2015) petunjuk. Tanda-tanda tersebut bisa menjadi bagian dari tenda, atau bisa berdiri sendiri yang diletakkan di dalam tenda. Tanda petunjuk tersebut umumnya adalah: masuk, keluar, tempat sampah, tempat cuci, awas bahaya api, dan lain-lain. Diberi Lambang institusi sebagai identitas bahwa produk ini didesain oleh institusi yang bersangkutan. Lambang PMI dan tulisan "Dapur Umum" sebagai identitas fungsi produk tersebut.

Dalam produk dapur umum ini material penyusunnya terdiri dari:

1. Lantai, menggunakan flooring sebagai alas dengan system puzzle knockdown, sehingga mudah dibawa dan dibersihkan. Dimensi flooring adalah panjang 60 $\mathrm{cm}$, lebar $60 \mathrm{~cm}$, dan tebal $5 \mathrm{~cm}$. lebar dan panjang komponen lantai ini disesuaikan dengan dimensi keramik yang ada, sehingga bila kondisi tertentu bisa diganti dengan keramik yang ukurannya ada di pasaran.

2. Dinding. Material untuk dinding dari kain. Kain yang tersedia antara lain terpal jenis Uno, nylon, Terpal Plastik /
Tarpauline Plastic. Bahan yang dipakai adalah terpal jenis Uno. Bahan jenis ini memiliki jaringan serat kuat, tahan terhadap jamur, mudah dibentuk, dan ketersediaan di pasaran mudah.

3. Atap. Bahan untuk atap sama dengan bahan untuk dinding, karena dapurnya jenis tenda, sehingga dinding dan atap sebagai satu kesatuan.

4. Kerangka atap. Kerangka atap menggunakan pipa hollow $25 \mathrm{~mm}$.

5. Kerangka dinding. Menggunakan pipa hollow $45 \mathrm{~mm}$, disusupi pipa hollow $40 \mathrm{~mm}$. Penggunaan dua pipa yang berbeda dimensi ini supaya bisa disetting tinggi rendahnya dapur sesuai kebutuhan, serta untuk memudahkan perakitan dan pengepakan dalam pengiriman atau penyimpanan.

6. Kerangka penguat. Menggunakan pipa hollow $25 \mathrm{~mm}$.

Hasil desain dapur umum berupa prototypeproduk. Terdiri dari beberapa komponen produk sehingga mudah untuk diurai, mudah dirakit, bisa didirikan di lokasi dekat bencana, mampu mengakomodasi kebutuhan dan aktifitas petugas. 


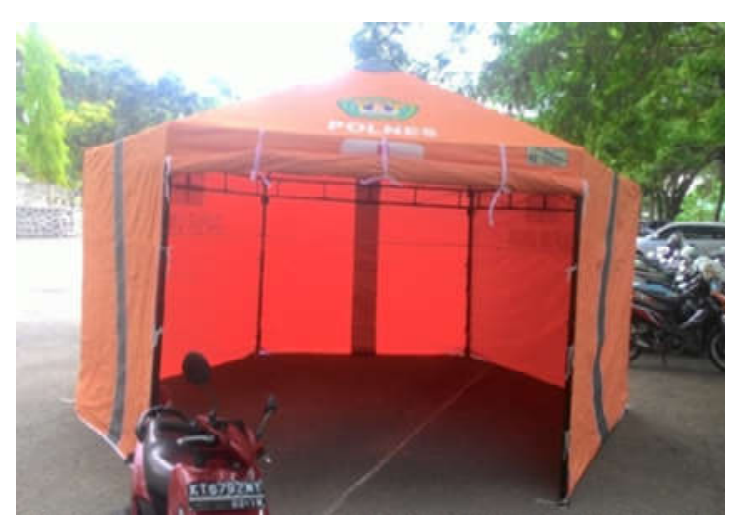

Gambar 10.

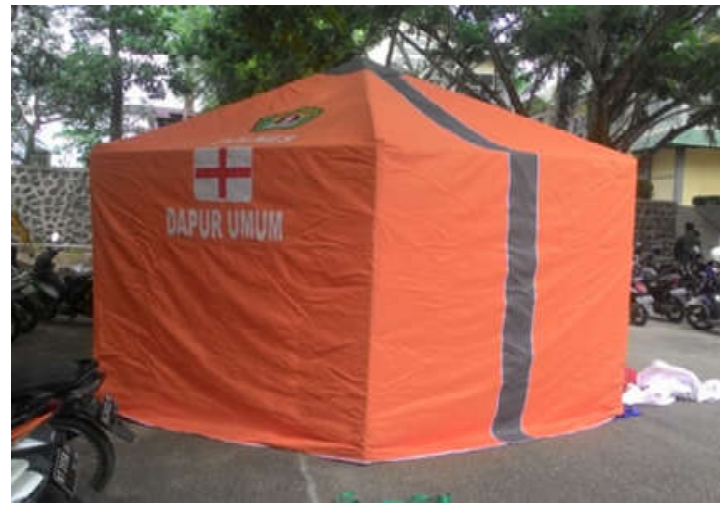

Gambar 11.

Gambar 10 - 11.

Prototype produk, Sumber: Penulis (2015)

Bentuknya modular sehingga portable, mudah dibawa untuk didistribusikan dan mudah untuk penyimpanan, serta mudah untuk perawatan sehingga menekan biaya perawatan.

\section{SIMPULAN}

Salah satu unsur dalam manajemen penanggulangan bencana alam adalah adanya dapur umum. Dapur umum digunakan untuk mobilisai bantuan berupa penyaluran kebutuhan makanan dan logistik untuk petugas dan korban. Ada bermacam-macam jenis dapur umum, dengan segala kelebihan dan kekurangan masing-masing. Dalam penelitian ini dihasilkan purwarupa desain dapur umum untuk bencana alam dalam bentuk tenda. Bentuktenda dipilih karena memiliki beberapa kelebihan,antara lain, mudah dipasang, mudah dibongkar, ringan, portable, modular, bisa didistribusikan ke lokasi bencana. Dapur umum yang dihasilkanbisa dikombinasikan dengan beberapa dapur sejenis membentuk formasi bangunan sesuai kondisi dan kebutuhan di lapangan.

Purwarupa desain dapur umum ini masih memerlukan beberapa pembenahan agar lebih sempurna. Yaitu penggunaan bahan dindingdari kain yang lebih kuat, susunan kerangkanya disempurnakan antar sambungan, supaya dihasilkan sambungan dan tekukan yang rapi. Warna kain bagian dalam dapur diberi warna yang menyejukkan, seperti hijau, biru, abu abu atau warna rendah cahaya yang lain. Warna dalam dapur dalam prototype sekarang yang terang seperti warna luar, membikin mata cepat lelah, dan terkesan panas. Exhaust perlu didesain dudukan dan spesifikasi yang baku, untuk memperlancar sirkulasi udara di dalamnya. Pembenahan-pembenahan pada purwarupa ini ditujukan agar lebih sempurna produk agar siap untuk diproduksi massal sehingga bisa dipasarkan.

\section{Daftar Pustaka}

Arie Sulistiyanto

2009 Desain Dapur Umum Dengan Konsep Kompaktor, Jurnal Desain Idea, Vol 7. No. 2, 2009

Diandra Pandu Saginatari

2011 Dapur Bersih dan Dapur Kotor, Skripsi Fakultas Teknik, Departemen Arsitektur, Universitas Indonesia, Jakarta

Eko Nurmianto,

Ergonomic Design for Mobile and Portable Emergency Disaster Kitchen, $3^{\text {rd }}$ International Conference on Opera- 
tions and Supply Chain Management, Malaysia

Panero, J.,

1979 Human Dimension E Interior Space atau DimensiManusiadanRuang Interior, terjemahan Djoeliana

\section{Sumber lain:}

Kurniawan.

2003 Erlangga, Jakarta

www.digilib.its.ac.id/Terbit Setya/Desain dapur Umum Untuk Penanganan Bencana Alam Dengan Konsep Modul.htm, 17 April 2013
www.digilib.its.ac.id/Dyat Agung Syahputra/Desain dapur Umum Untuk Pasca Bencana Dengan Konsep Karavan.htm, 17 April 2013

www.its.ac.id/Rancang Dapur Umum Portable untuk Korban Bencana.htm, 29 April 2013

www.dinassosialpropinsikaltim.go.id/ kaltim resmi punya perda penanggulangan bencana daerah.htm, 29 April 2013

www.RescueForHumanity/Pengantar Dapur Umum.htm, 22 Juni 2013 